\title{
Hydraulic energy storage of wind power plants
}

\author{
Boboraim Urishev ${ }^{*}$, Rumiya Beytullayeva, Asror Umirov, and Oybek Almardonov \\ Karshi engineering-economics institute, Karshi, Uzbekistan
}

\begin{abstract}
The article discusses information on the need to accumulate energy from renewable sources to improve their efficiency, as well as some examples of the integration of systems for hydraulic energy storage and renewable sources, which ensure an increase in the reliability and volume of energy generation. The method for determining the parameters of a wind power plant's hydraulic energy storage system, which is based on the balance of the daily load produced and spent on energy storage, is presented. With changing daily loads, this technique makes it possible to determine the main parameters of the complex, including the volume of accumulated water, the coefficient of energy use of the wind power station. A functional diagram of the programmed control of the pumped storage and wind power plant parameters for the optimal use of the wind potential in hydraulic energy storage is presented. Based on the results of calculations using the proposed method, the main parameters of the system based on pumped storage and wind power plant with a capacity of $100 \mathrm{MW}$ were determined, the efficiency of hydraulic energy storage was determined in comparison with lithium-ion batteries.
\end{abstract}

\section{Introduction}

Traditional centralized power systems have significant drawbacks, such as significant energy losses due to the remoteness of some consumers, insufficient flexibility of the production process caused by its low maneuverability, lack of proper regulation of consumption, and energy tariffication. These disadvantages ultimately lead to an increase in fuel consumption, the degree of $\mathrm{CO}_{2}$ emissions, and the cost of energy produced. In this regard, recently, localized power systems such as microgrids, smart grids, distributed generation clusters, and virtual power plants are increasingly being used. Such systems can help solve very important problems, such as optimization, stabilization, the flexibility of the power system, integration of renewable energy sources, and "smart" control centers in the process of energy production and distribution [1-3]. Accumulation of an excess part of the energy for use in peak hours is a necessary procedure for local power systems, for which electrochemical, regenerative - fuel, and other energy storage devices are most often used.

Currently, the method of hydraulic energy storage has the best performance among storage devices. It is considered an effective direction for expanding the possibilities of using renewable energy sources, even though the decisive factors are the availability of sufficient natural resources, conditions for constructing reservoirs, and obtaining the necessary pressure $[4,5]$.

\footnotetext{
*Corresponding author: bob_urishev@mail.ru
} 
The development of integration of systems for the use of wind power plants (WPP) and hydraulic storage can increase the share of wind energy on average up to $20 \%$ in the total energy consumption [6]. Investigating this issue depending on the power consumption, the author of [7] asserts that up to $80 \%$ of wind energy can be realized in power supply systems, provided that pumped storage is used. An increase in the utilization rate of wind energy is also observed with an increase in energy storage duration, so, for example, up to $90 \%$ of wind energy can be used to accumulate water in the upper reservoir for $1 \ldots 3$ days [8].

In [9], an overview of the prospects for the development of hydraulic energy storage in the light of sustainable development was presented. According to this review, the most promising direction is the hybrid use of pumped storage power plants (PSP) of low power in a complex with wind and solar power plants. This is confirmed by the study results, indicating an increase in the reliability and volume of energy generation by hybrid solar and wind power plants compared to their work [10].

The authors of [11-13] concluded that an integrated system for the use of wind energy and PSP under certain conditions is the most economically and technically competitive technology in different geographic latitudes.

In [14], the issues of large-scale integration of renewable energy sources using pumped storage power plants into the Irish power system are considered on the example of the use of wind energy. The main key issues were considered: capital costs, optimal parameters, and aspects of the operation. The study results showed that the PSP allows increasing the efficiency of the use of renewable energy sources and reduces operating costs.

The integration of a PSP into a wind power plant system in Spain increases the profitability of this integrated system and minimizes wind energy losses [15].

The work [16-18] studied the possibility of maximum use of wind energy in combination with existing autonomous thermal power plants by using pumped storage power plants in the isolated energy system of Karpathos' islands Kasos, located in the Southeast Aegean Sea. The results of this study proved the economic feasibility of using low-power wind turbines to power pumping units of pumped storage power plants, even without taking into account the undoubted environmental benefits.

With the optimal integration of wind energy with a pumped storage power plant in lake Turkana (Kenya), the hydraulic energy storage of the wind turbine made it possible to reduce the energy deficit to $46 \%$, which is equivalent to receiving an income of more than 10 thousand dollars per day [19].

\section{Methods}

A schematic of a low-power PSP with a wind turbine is shown in figure 1 . 


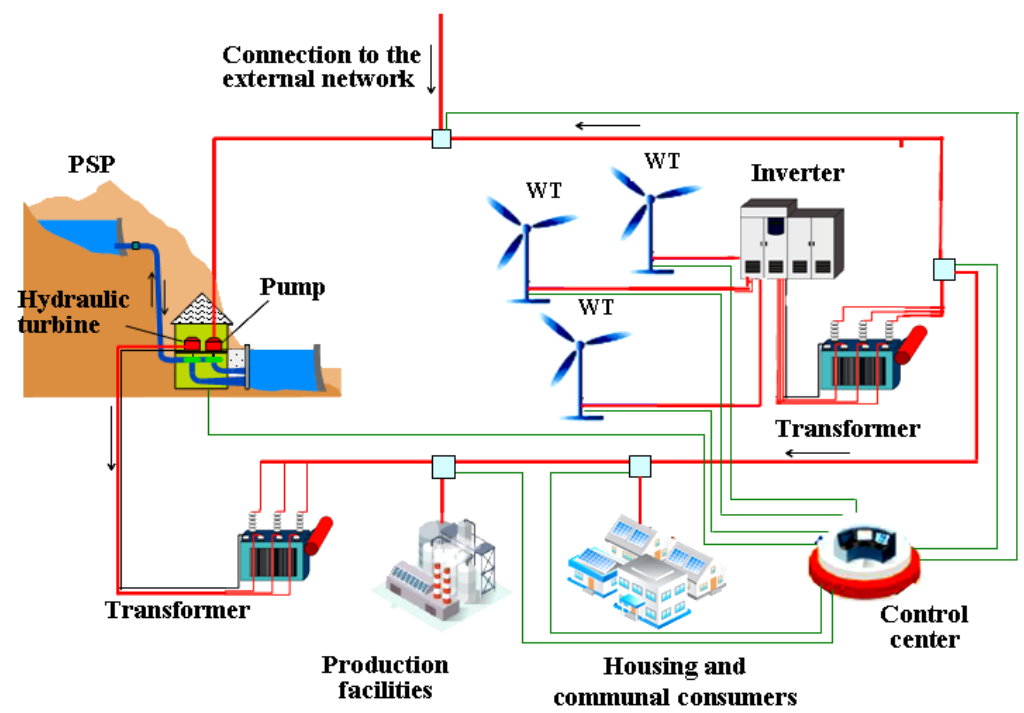

Fig. 1. Scheme of low power pumped storage power plant with wind farm

According to this scheme, the main energy producer is a wind power station (WPS), consisting of several wind turbine, which, in hours of minimum energy consumption, having excess power, supplies power to pumping units (PU) of a pumped storage power plant for accumulating water in the upper reservoir. During peak hours of energy consumption, when the wind turbine's power is not sufficient, water from the upper reservoir is supplied to the hydro turbines to generate energy and then to the lower reservoir.

With known values of the power of the wind flow, the installed power of the wind farm must be determined based on the values of the daily load schedule. Assuming that the energy generated by the wind turbines is used for two purposes: the main part of the energy is directed to the consumer's needs, and the excess is used for storage, i.e., to power the PU. The average graphs of the daily load and energy of WPS with a maximum power of 100 MW are shown using the example shown in fig. 2.

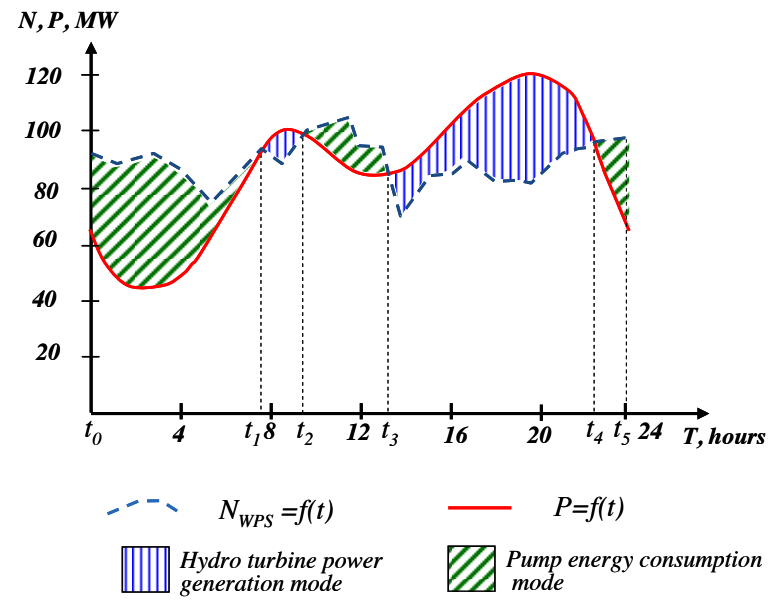

Fig. 2. Schedule of the operating mode of a low-power PSP with a WPS 
For this example, the following expression is valid, which follows from the equation for balancing the daily load and the generated energy.

$$
\Im_{W P S} \cdot \eta_{E}=\int_{0}^{T} P(t) d t,
$$

where $Э_{W P S}$ is generated energy by WPS over time $T$;

$\eta_{E}$ is efficiency in the process of transferring energy to the consumer;

$P(t)$ is load consumption values at points in time $t$. From here, we can determine the average power of the WPS over time $T$.

$$
N_{W W S a v}=\frac{\int_{0}^{T} P(t) d t}{T \cdot \eta_{\mathrm{E}}},
$$

The following relationship can determine the installed capacity of a wind farm

$$
N_{W P S}=N_{W T} \cdot n
$$

where $n$ is number of wind turbines.

Determination of the type, brand, and the number of installed wind turbines must be carried out based on a feasibility study, taking into account local conditions based on considering several options.

All options must meet the condition specified in (1).

The obtained values of the power of the WPS $N_{W P S}$, depending on the time $t$, can be used to determine the PSP mode with the WPS (see fig. 2. graph $N_{W P S}=f(T)$ ).

The condition for the energy balance of a PSP with a WPS in its pumping mode, i.e., when there is an excess of the generated energy overconsumption, it is described by the following balance equation

$$
\sum_{i=1}^{n} N_{\mathrm{WPSi}_{\mathrm{i}}} t_{i}-\sum_{i=1}^{n} P_{i} \cdot T=\sum_{i=1}^{n} N_{\mathrm{Pi}} t_{i}=Э_{P}
$$

$N_{P}, \ni_{P}$ is power and energy consumption in pumping mode.

From here, we determine the maximum volume of the upper reservoir according to the well-known formula

$$
V_{\max }=\frac{367 \cdot \eta_{\mathrm{pum}}\left(\sum_{i=1}^{n} N_{\mathrm{WPSi}} t_{i}-\sum_{i=1}^{n} P_{i} \cdot t_{i}\right)}{H_{P i}}
$$

From (6) it can be seen that the volume of the reservoir $V$ is determined in direct dependence on the amount of energy that must be accumulated and in inverse dependence on the pressure $H_{P}$.

The volume of water in the upper and lower reservoirs during the day will be variable and depends on the operating time of the PSP in turbine and pumping modes. To assess changes in water volumes, graphs $W_{l e v}=f(V)$ are used, characterizing the dependence of the water level $W_{l e v}$ in reservoirs on their volumes $V$. 
The excess capacity of the PSP $N_{P}=N_{W P S}-P$ must be used to power the PSP pumping the volume of water $\Delta V_{H}$ into the upper reservoir, for example, according to the graph in fig. 2 during the time from $t_{0}$ to $t_{1}, t_{2}$ to $t_{3}$ and from $t_{4}$ to $t_{5}$.

When there is not enough WPP power to cover the daily load schedule, the lack of power $N_{H}=P-N_{W P S}$ is compensated by transferring the PSP to the power generation mode with water supply to the hydro turbines, which will generate the missing electricity. For example, according to the schedule in fig. 2, during the time from $t_{1}$ to $t_{2}$ and $t_{3}$ to $t_{4}$. It is convenient to present the calculation results in tabular form (Table 1).

Table 1. Determination of the capacity of the PSP

\begin{tabular}{|c|c|c|c|c|}
\hline $\begin{array}{c}\text { Time } \\
\text { of day }\end{array}$ & $\begin{array}{c}\text { Daily load } \\
\text { of electric } \\
\text { power } \mathrm{P}, \\
\mathrm{kW}\end{array}$ & $\begin{array}{c}\text { WPS power } \\
\mathrm{N}_{\mathrm{WPS}}, \mathrm{kW}\end{array}$ & $\begin{array}{c}\text { Pumping } \\
\text { power } \\
\text { regime, } \\
\mathrm{N}_{\mathrm{P}}, \mathrm{kW}\end{array}$ & $\begin{array}{c}\text { Turbine power, } \\
\mathrm{N}_{\mathrm{H}}, \mathrm{kW}\end{array}$ \\
\hline $\mathrm{t}_{0-1}$ & $\mathrm{P}_{\mathrm{i}(0-1)}$ & $\mathrm{N}_{\mathrm{WPS} \mathrm{i}(0-1)}$ & $\mathrm{N}_{\mathrm{P} \mathrm{i}(0-1)}$ & - \\
\hline $\mathrm{t}_{1-2}$ & $\mathrm{P}_{\mathrm{i}(1-2)}$ & $\mathrm{N}_{\mathrm{WPS} \mathrm{i}(1-2)}$ & - & $\mathrm{N}_{\mathrm{Hi}(1-2)}$ \\
\hline $\mathrm{t}_{2-3}$ & $\mathrm{P}_{\mathrm{i}(2-3)}$ & $\mathrm{N}_{\mathrm{WPS} \mathrm{i}(2-3)}$ & $\mathrm{N}_{\mathrm{P} \mathrm{i}(2-3)}$ & - \\
\hline $\mathrm{t}_{3-4}$ & $\mathrm{P}_{\mathrm{i}(3-4)}$ & $\mathrm{N}_{\mathrm{WPS} \mathrm{i}(3-4)}$ & - & $\mathrm{N}_{\mathrm{H} \mathrm{i}(3-4)}$ \\
\hline $\mathrm{t}_{4-5}$ & $\mathrm{P}_{\mathrm{i}(4-5)}$ & $\mathrm{N}_{\mathrm{WPS} \mathrm{i}(4-\mathrm{T})}$ & $\mathrm{N}_{\mathrm{Pi}(4-\mathrm{T})}$ & - \\
\hline
\end{tabular}

Table 1 continued

\begin{tabular}{|c|c|c|c|c|}
\hline $\begin{array}{c}\text { Time } \\
\text { of day }\end{array}$ & $\begin{array}{c}\text { The amount } \\
\text { of electricity } \\
\text { in pumping } \\
\text { mode, EN, } \\
\mathrm{kW} / \mathrm{h}\end{array}$ & $\begin{array}{c}\text { The amount of } \\
\text { electricity in } \\
\text { turbine mode, } \\
\mathrm{ET}, \mathrm{kWh}\end{array}$ & $\begin{array}{c}\text { Volume water } \\
\text { supply upper } \\
\text { reservoir, } \mathrm{V}_{\mathrm{H}}, \\
\mathrm{m}^{3}\end{array}$ & $\begin{array}{c}\text { Volume water } \\
\text { supply lower } \\
\text { reservoir, } \mathrm{V}_{\mathrm{T}}, \mathrm{m}^{3}\end{array}$ \\
\hline $\mathrm{t}_{0-1}$ & $Э_{\mathrm{P}(0-1)}$ & - & $\Delta \mathrm{V}_{\mathrm{P}(0-1)}$ & - \\
\hline $\mathrm{t}_{1-2}$ & - & $Э_{\mathrm{H}(1-2)}$ & - & $\Delta \mathrm{V}_{\mathrm{H}(1-2)}$ \\
\hline $\mathrm{t}_{2-3}$ & $Э_{\mathrm{P}(2-3)}$ & - & $\Delta \mathrm{V}_{\mathrm{P}(2-3)}$ & - \\
\hline $\mathrm{t}_{3-4}$ & - & $Э_{\mathrm{H}(3-4)}$ & - & $\Delta \mathrm{V}_{\mathrm{H}(3-4)}$ \\
\hline $\mathrm{t}_{4-5}$ & $Э_{\mathrm{P}(4-5)}$ & - & $\Delta \mathrm{V}_{\mathrm{P}(4-5)}$ & - \\
\hline
\end{tabular}

The amount of electricity is determined by discrete summation of the products $N \cdot \Delta t$ in fixed time intervals, for example, for the period $t_{0-1} \ni_{P(0-1)}=\sum_{i=1}^{n} N_{P i} \cdot \Delta t_{i}$, and for the period $t_{1-2} \quad \ni_{H(1-2)}=\sum_{i=1}^{n} N_{H i} \cdot \Delta t_{i}$

The volume of water supplied by the PU to the upper reservoir in the first period of operation can be determined as follows

$$
\Delta V_{P(0-1)}=\frac{367 \cdot \ni_{\mathrm{P}(0-1)} \cdot \eta_{p u m}}{H_{P(0-1)}},
$$
mode.

where $H_{P(0-1)}, \eta_{\text {pum }}$ are head and efficiency of pumped storage power plant in pumping

With the alternating supply and withdrawal of water from reservoirs, the water level in them changes and, therefore, the pressure values of the PSP will be different, and they are determined by the following relationship [20] 


$$
H_{H i, P i}=H_{\mathrm{Hi}, P i}^{G} \pm \Delta H_{i}
$$

where $\Delta H_{i}$ is the pressure loss in the water conduits, which depends on the flow rate of the pump or turbine $Q$ and can be calculated using well-known hydraulic calculation methods. In the above formula, the $(+)$ sign corresponds to the pumping mode, and the (-) sign to the turbine mode, $H^{G}$ is geometric head.

When the time of energy insufficiency of the WPP $\mathrm{t}_{1-2}$ comes, the HP will be stopped, and the hydro power plants (HPP) will be put into operation with the supply of a volume of water $\Delta V_{H(1-2)}$ (fig. 2 and table 1)

$$
\Delta V_{H(1-2)}=\frac{367 \cdot \ni_{H(1-2)}}{H_{H(1-2)} \cdot \eta_{t u r}},
$$

$H_{H(1-2)}, \eta_{t u r}$ is head and efficiency of pumped storage power plant in turbine mode.

The volume of water in reservoirs corresponding to the operating mode of the PSP and WPP, shown in fig. 2 can be determined by the maximum value of $\Delta V_{H}$ or $\Delta V_{P}$ according to table 1 .

The water flow rate of the PSP in turbine and pumping modes $Q_{H}$ and $Q_{P}$ at fixed times $t_{i}$ can be determined based on the values of powers and heads according to the following formulas

$$
Q_{\mathrm{Hi}}=\frac{N_{H i}}{9,81 \cdot \eta_{t u r} \cdot H_{H i}}, \quad Q_{\mathrm{Pi}}=\frac{N_{P i} \cdot \eta_{\mathrm{pum}}}{9,81 \cdot H_{P i}}
$$

One of the specific energy indicators is the utilization rate of the generated and consumed energy, calculated according to the following relationship

$$
K_{t}=\left(Э_{W P S}-Э_{P}+Э_{H}\right) / Э_{W P S}
$$

Thus, we can summarize that the above method allows you to determine the parameters of the pumped storage power plant, the maximum corresponding to the capacity of the wind farm, and the daily electrical load.

For this complex, a functional diagram of the execution of operations for the programmed control of the parameters of PSP and WPP has been developed (fig. 3).

At the first stage of the complex functioning, to resolve the issue of "accumulate or generate energy", the power value of the $N_{W P S}$ at time t compared with the corresponding power of the daily load schedule $P$, because of which one of three possible operations performed.

a) $\quad N_{W P S}=P$, at the same time, the PSP does not work; the loads are covered by the energy of the WPS.

b) In the case of $N_{W P S}>P$, an excess of energy is observed, which must be directed to feed the PU to accumulate water in the upper reservoir.

c) The state of the $N_{W P S}<P$ shows the lack of generated energy, which precedes the start of the power plant with a water supply from the upper reservoir. 


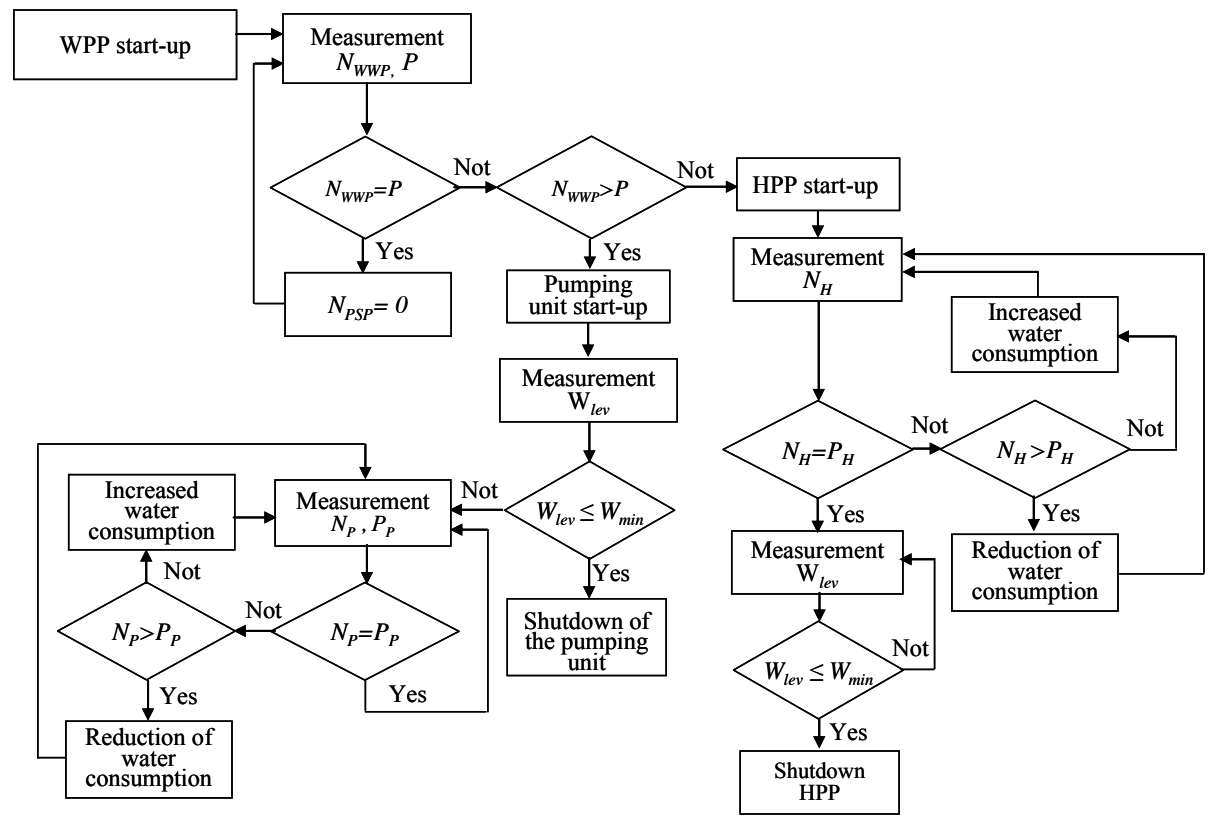

Fig. 3. Functional diagram of PSP with WPS

Thus, the main task of the first stage is to determine the time and conditions for the startups of the HPP and PU according to the parameters of the $N_{W P S}$ and $P$.

The second stage begins with the start-up of the PU with a full or almost full volume of water in the lower reservoir. During the operation of the pumps, it is necessary to control the water level in the lower reservoir and the power of the pump to perform the following operations:

- $\quad$ when the water level drops to the level of the dead volume, the PU is switched off;

- suppose NP does not correspond to the PH value, which is characterized as the difference in the capacities of the PH $=$ NWPS. In that case, $P$ (excess power of the WPP, directed to power the PU), an operation is performed to increase or decrease the flow rate of water supplied to the PU to achieve the correspondence $N_{P}=P_{P}$.

At the third stage, when $N_{W P S}<P$, to replenish the missing part of the load, the hydro power plant is launched. During the HPP operation, $N_{H}$ is regularly measured, and it is compared with the value of $P_{H}$, which characterizes the difference $P_{H}=P-N_{W P S}$. If these values are equal, this means that the power of the power plant is sufficient to cover the load curve, and the position of the water level in the upper reservoir is checked, i.e., $W_{l e v} \leq W_{\min }$. If the water level drops below $W_{\min }$, the power plant is turned off, and the pumped storage power plant switches to pumping mode. In case of non-compliance of $N_{H} \neq P_{H}$, a command is given to increase or decrease the flow rate of water supplied to the power plant to achieve the balance $N_{H}=P_{H}$.

\section{Results and discussion}

Consider a certain local power system with a daily demand from 800 to $1050 \mathrm{MW} \cdot \mathrm{h}$ based on a wind farm, generating $850 \ldots 1100 \mathrm{MW} \cdot \mathrm{h}$ of electricity per day, the schedules of $N_{W P S}$ $=f(T)$ and $P=f(T)$ of which are shown in fig. 2. Based on the results of calculations performed using the characteristic graphs $N_{W P S}=f(T)$ and $P=f(T)$, the following indicators were obtained:

1. The amount of accumulated energy is $\ni_{P}=110 \ldots 150 \mathrm{MW} \cdot \mathrm{h}$, and the generated 
energy $\ni_{H}=76 \ldots 104 \mathrm{MW} \cdot \mathrm{h}$.

2. Reservoir volume $V=8000000 \ldots 10230000 \mathrm{~m}^{3}$

3. Installed capacity of WPP $N_{W P S}=100 \mathrm{MW}$

3. Installed capacity of PU and HPP $N_{P}=55 \mathrm{MW}, N_{H}=35 \mathrm{MW}$

4. The average operating time of the PU is 12.5 hours, and the HPP $-11,5$ hours.

5. Average head $H_{P}=40,0 \mathrm{~m}, H_{H}=38,5 \mathrm{~m}$.

The calculation results show that the amount of accumulated energy is $13,0 \ldots 13,6 \%$ of the generated, for which it is necessary to build a 55 MW PSP with two reservoirs with volumes of $8,0 \ldots 10,23$ million $\mathrm{m}^{3}$. The energy utilization factor of the WPS is $0,91 \ldots$ 0,96 , which is one of the highest indicators for this type of power plant [7].

To answer the question of how economically beneficial it is, we compare the costs of hydraulic energy storage with the costs of its storage by lithium-ion batteries, which are one of the most common storage devices in 2019. According to Lazard's financial consulting company, cited in [21], the unit costs of lithium-ion batteries are $\$ 204 \ldots 275 / \mathrm{kWh}$, and the PSP is $\$ 177 \ldots 186 / \mathrm{kWh}$. These costs include the cost of storing capacity for 4 hours for lithium-ion batteries and 16 hours for a pumped storage plant. With average values of these specific indicators (for example, with their difference of $\$ 60 / \mathrm{kWh}$ ), the economic effect from the use of PSP in the considered power system compared with lithium-ion batteries is $\$ 6,6 \ldots 9,0$ million per day.

\section{Conclusions}

1. A method has been developed for determining the parameters of the PSP and WPP complex, based on ensuring the balance of generated, consumed, and accumulated energy in the power system.

2. A functional diagram of the programmed control of the parameters of pumped storage power plants and wind power plants has been developed, making it possible to achieve optimal use of the wind potential by hydraulic energy storage.

3. The results of comparative calculations of the costs of energy storage have shown the economic efficiency of PSPP in comparison with lithium-ion batteries, estimated at \$ 6.6 ... 9.0 million per day.

\section{References}

1. Peter Alstone, Dimitry Gershenson, Daniel M. Kammen. Decentralized energy systems for clean electricity access. Nature climate change, vol. 5, https://rael.berkeley.edu/wp-content/uploads/2016/04/Alstone-Gershenson-KammenNatureClimateChange-EnergyAccess.pdf. (2015).

2. United States Environmental Protection Agency. Distributed Generation of Electricity and its Environmental Impacts. Washington, DC 20460, https://www.epa.gov/energy/distributed-generation-electricity-and-its-environmentalimpacts\#ref1. (2019).

3. Urishev B (2019) Decentralized Energy Systems, Based on Renewable Energy Sources. Applied Solar Energy, vol. 55, no. 3, pp. 207-212. DOI: 10.3103/S0003701X19030101

4. Shafiqur Rehman, Luai M. Al-Hadhrami, Md. Mahbub Alam. (2015) Pumped hydro energy storage system: A technological review. Renewable and Sustainable Energy Reviews, no. 44, pp. 586-598.

5. Kaldellis JK, Kavadias KA. Optimal wind-hydro solution for Aegean Sea islands' electricity-demand fulfilment. Appl Energy, no.70(4), pp.333-354. (2001). 
6. Weisser D, Garcia RS. 2005 Instantaneous wind energy penetration in isolated electricity grids: concepts and review. Renewable Energy, no. 30(8), pp. 1299-1308.

7. Jacob T. Pumped storage in Switzerland - an outlook beyond, Stucky Consulting Engineers, The Economist. (2014).

8. Bakos G.C. Feasibility study of a hybrid wind/hydro power-system for low- cost electricity production. Appl Energy, no.72 (3-4), pp. 599-608. (2002).

9. Ardizzon G, Cavazzini G, Pavesi G. A new generation of small hydro and pumpedhydro power plants: advances and future challenges. Renewable Sustainable Energy Rev. no. 31, pp. 746-61. (2014).

10. Hoicka CE, Roewlands IH. Solar and wind resource complementarity: advancing options for renewable electricity integration in Ontario, Canada. Renewable energy, no. 36, pp. 97-107. (2011).

11. Caralis G, Rados K, Zervos A. On the market of wind with hydro-pumped storage systems in autonomous Greek islands. Renewable Sustainable Energy Rev. no.14, pp. 2221-2226. (2010).

12. Dursun B, Bora A. The contribution of wind-hydro pumped storage systems in meeting Turkey's electric energy demand. Renewable Sustainable Energy Rev. no. 14 (7), pp. 1979-1988. (2010).

13. Tuohy A, O'Malley M. 2011 Pumped storage in systems with very high wind penetration. Energy Policy, no. 39(4), pp. 1965-1974.

14. Connolly D, Lund H, Mathiesen BV, Pican E, Leahy M. The technical and economic implications of integrating fluctuating renewable energy using energy storage. Renewable energy, no. 43, pp. 47-60. (2012).

15. Varkani AK, Daraeepour A, Monsef H. A new self-scheduling strategy for integrated operation of wind and pumped-storage power plants in power markets. Appl Energy, no. 88, pp. 5002-5012. (2011).

16. Anagnostopoulos JS, Papantonis DE. Study of pumped storage schemes to support high RES penetration in the electric power system of Greece. Energy, no. 45(1), pp. 416-423. (2012).

17. Katsaprakakis DA, Christakis DG, Pavlopoylos K, et al. Introduction of a wind pumped storage system in the isolated insular power system of Karpathos - Kasos. Appl Energy no. 97, pp. 38-48. (2012).

18. Katsaprakakis DA, Christakis DG, Stefanakis I, Spanos P, Stefanakis N. Technical details regarding the design, the construction and the operation of seawater pumped storage systems. Energy, no. 55, pp. 619-630. (2013).

19. Murage M W, Anderson C L. Contribution of pumped hydro storage to integration of wind power in Kenya: an optimal control approach. Renewable energy, no. 63, pp. 698-707. (2014).

20. Urishev B (2019) Selection of Parameters of Pumped Storage Power Plants at Large Pumping Stations for Water Use. Applied Solar Energy, vol. 54, no. 6, pp. 477-480. DOI: 10.3103/S000 3701X18 060166

21. David G. Victor. (2019) Pumped Energy Storage: Vital to California's Renewable Energy Future Release. https://www.energy.senate.gov/services/files/F5F5EDF0E298-4843-BAA5-CC8605586484 